\title{
CO-DETERMINATION OF TWO ANTIPARASITICS DRUGS BY DERIVATIVE SPECTROPHOTOMETRY AND ITS PHOTODEGRADATION STUDIES
}

\author{
CÉSAR SOTO* ${ }^{* 1}$, ROMINA OTIPKA², DAVID CONTRERAS ${ }^{1}$, JORGE YÁÑEZ ${ }^{1}$, M. INÉS TORAL ${ }^{2}$ \\ ${ }^{1}$ Department of Analytical and Inorganic Chemistry, Faculty of Chemical Sciences, University of Concepción, PO Box: 160-C, Concepción, Chile. \\ ${ }^{*}$ Address correspondence to this author at the Department of Inorganic and Analytical Chemistry, Faculty of Chemical Sciences, \\ University of Concepción, PO Box: 160-C, Concepción, Chile. \\ ${ }^{2}$ Department of Chemistry, Faculty of Sciences, University of Chile, PO Box: 653, Santiago, Chile.
}

(Received: March 3, 2013 - Accepted: June 12, 2013)

\begin{abstract}
This work proposes a method for the co-determination of praziquantel and fenbendazole in veterinary pharmaceutical formulations (VPF) by second-derivative spectrophotometry at $226.4 \mathrm{~nm}$ (Zero-crossing method) and $324.6 \mathrm{~nm}$ (Graphic method), respectively. The excipients commonly used in VPF do not interfere. To obtain the optimal determination conditions, studies of solvent and light effects, were performed. The results of the light effects show that the expose of both drugs to indirect light and darkness does not produce any chemical change, since their zero-order spectra remained unchanged during the experiment. However, the exposition to the direct light only affects the fenbendazole. The zero order spectrum of FBZ in EtOH-HCl, present two broad bands (200 to $240 \mathrm{~nm}$ and 260 to 330 $\mathrm{nm}$ ), these signals disappear and appear others totally different, at $230 \mathrm{~nm}$ and other with two peaks (285 and $295 \mathrm{~nm})$. The FT-IR spectrum shows characteristics signals of the FBZ structure as the amide-NH group $\left(3336.3 \mathrm{~cm}^{-1}\right)$, this signal disappear indicating the bond break of the amide group caused by the exposition to sunlight for a time. These spectral changes evidenced a structural transformation as a result of photochemical decomposition in acid medium.
\end{abstract}

Keywords: Fenbendazole; Praziquantel; Derivative Spectrophotometry; Veterinary Formulations; Photochemical Decomposition.

\section{INTRODUCTION}

The antiparasitic are drugs that have been used for about 50 years in crop protection, human and animal health. The treatment of antiparasitic diseases is a topic of great importance in these days for the pharmaceutical industry, because it becomes increasingly necessary to improve the pharmaceutical formulations due to the mix presentation of these diseases in many animals. The compounds of antiparasitic can include benzimidazoles and pyrazinoisoquinoline derivatives. The antihelminthics are widely used in veterinary medicine to treat gastrointestinal infections ${ }^{1}$ and in food-producing animals, and therefore, could be hazardous to humans. Part of the clinical efficacy of the antiparasitic depends on its penetration and of concentrations achieved within the cells of the parasite. The application of the treatment in young cattle, produce an antiparasitic immunity. Since the antihelminthic spectra of most drugs used for treatment is limited, combinations of more than one active ingredient are required to control helminthic infections ${ }^{2}$.In this context the mix of two drugs such as Fenbendazole, methyl N-(6-phenylsulfanyl-1H-benzoimidazol-2-yl) carbamate, (FBZ) (Fig.1a), this drug is thought to bind to tubulin and thereby preventing its polymerization to form microtubules, but it also inhibits fumarat reductase and glucose transport. As a result, parasites may die of starvation ${ }^{3}$ and Praziquantel, (RS)-2-(Cyclohexyl-carbonyl)-1,2,3,6,7,11,b-hexahydro4H-pyrazino (2,1-alpha) isoquinoline-4-one, (PZQ) (Fig.1b), is a synthetic antihelminthic agent, used against many cestodes, and for the treatment of schistosomiasis, as well other fluke infections pathogenic to humans $\mathrm{s}^{4,5}$, are commonly used in domestic animals for the prevention and control of a wide variety of parasitic diseased, in a pharmaceutical combination with a 1:10 mass ratio.

There are studies where is proved that these drugs are more effective together than separately, one example of that is an evaluation of therapeutic effects against coenurosis in sheep ${ }^{6}$ this study indicates the efficacy of coadministration of fenbendazole together with praziquantel against coenurosis, highlighting the benefits to the use of the combination of both drugs. The evaluation of the veterinary preparations require of the determination of their active ingredients in different samples such as drug formulations and biological matrices. Numerous methods for the quantification of either one or a mixture of FBZ and PZQ with others compounds has been reported in the literature, in biological matrices using techniques such as, liquid membrane and solid phase extraction with liquid chromatography electrospray mass spectrometry $\left(\mathrm{LC}\right.$ ES MS) ${ }^{7}$ liquid membrane extraction and liquid chromatography $(\mathrm{LC})^{8}$, high performance liquid chromatography (HPLC) ${ }^{9}, \mathrm{LC}^{10,11}$ polymer solid phase extraction coupled to square wave voltammetry at carbon fibre microelectrodes ${ }^{12}$, cathodic adsorptive stripping differential pulse voltammetry
$(\mathrm{CASDPV})^{13}$. In feeds and pharmaceutical formulations by techniques such as, CASDPV ${ }^{13}$, colorimetric method ${ }^{14}$, second derivative spectrophotometry and multivariated calibration methods ${ }^{15}$, amperometric detection with flow injection ${ }^{16}$, HPLC capillary electrophoresis ${ }^{17}$, HPLC ${ }^{18,19}$, gas liquid chromatography $(\mathrm{GLC})^{20}$, densitometric determination ${ }^{21}$, voltammetric determination with poly(3-methylthiophene)-modified glassy carbon electrode $^{22}$, voltammetric determination ${ }^{16,23}$, voltametric stripping methods ${ }^{24}$ and polarographic assay ${ }^{25}$.

(a)<smiles>COC(=O)Nc1nc2cc(Sc3ccccc3)ccc2[nH]1</smiles>

(b)<smiles>O=C(C1CCCCC1)N1CC(=O)N2CCc3ccccc3C2C1</smiles>

Figure 1. Molecular structure for (a) FBZ and (b) PZQ.

In veterinary pharmaceutical formulations, only the British Pharmacopoeia presents an official method for FBZ assay ${ }^{26}$. In $33^{\text {th }}$ United States Pharmacopoeia version, has been reported methods for the individual determinations of PZQ and FBZ, in pharmaceutical formulations for human treatments ${ }^{27,28}$. Although the determination of these drugs has been reported by several methods in conjunction with other veterinary drugs, there are not reported methods that consider the simultaneous determination of these drugs alone. The aim 
of this study was to develop and to validate analytical methods for the codetermination of FBZ and PZQ by derivative spectrophotometry in veterinary pharmaceutical formulations. This technique has been used successfully in the determination of the others drugs in different samples ${ }^{29,30}$.

\section{EXPERIMENTAL}

\section{Instruments}

Absorption spectra were recorded on a Shimadzu UV-1603 spectrophotometer. All samples were measured using a $1 \mathrm{~cm}$ path-length quartz cuvette. For all the tested solutions, the second derivative spectra were recorded on the range between 190-400 $\mathrm{nm}$ against solvent, using $0.2 \mathrm{~nm}$ sampling intervals and scanning of $480 \mathrm{~nm} / \mathrm{min}$. The spectral data were processed by software Shimadzu kit version 3.7 (P/N 206-60570-04). All solid samples were weighted with a $0.01 \mathrm{mg}$ of uncertainty using a Sartorius R 200D balance.

\section{Reagents}

Analytical standards of PZQ and FBZ were purchased from SigmaAldrich $^{\circledR}$. Stock solutions of PZQ and FBZ were prepared by dissolving the accurately weighed reference compounds in $\mathrm{HCl} 0.10 \mathrm{~mol} / \mathrm{L}$ in ethanol solution $(\mathrm{EtOH}-\mathrm{HCl})$ to give a final concentration of $1.0 \times 10^{-3} \mathrm{~mol} / \mathrm{L}$. These solutions were then serially diluted with the same solvent to achieve other ranges of concentrations for standard working solutions. The pharmaceutical product, Fentel ${ }^{\circledR}$ (Laboratory KUALCOS SRL, BA, Argentina) containing both compounds was also dissolved using the same solvent. Furthermore, in order to carry out a study of solvent, solutions of PZQ and FBZ were prepared dissolving the amount previously described for each drug in different solvents.

\section{Procedures}

\section{Calibration graphs of FBZ and $P Z Q$ in mixtures}

Aliquots of the stock solution of PZQ and FBZ were simultaneously diluted in EtOH-HCl $0.1 \mathrm{~mol} / \mathrm{L}$ to obtain a concentration range between 1.0 $\times 10^{-6}-6.0 \times 10^{-6} \mathrm{~mol} / \mathrm{L}$ for PZQ and $1.0 \times 10^{-5}-6.0 \times 10^{-5}$ for FBZ. The calibration procedures were determined for each drug in the presence of 5.0 $\times 10^{-5} \mathrm{~mol} / \mathrm{L}$ of FBZ and $5.0 \times 10^{-6} \mathrm{~mol} / \mathrm{L}$ of PZQ, respectively. In all cases, the corresponding absolute values of the second derivative spectra at 226.4 $\mathrm{nm}$ for PZQ and $324.6 \mathrm{~nm}$ for FBZ, were obtained and plotted versus the corresponding concentrations. The exposure to direct light (sunlight) of all working solutions, for a long time must be avoided.

Simultaneous determination of PZQ and FBZ in synthetic samples

The stock solutions of each drug were appropriately diluted to obtain solutions that contain molar ratios between 1:4 and 1:14 (PZQ: FBZ). For each solution, three repetitions were made. Then, the second derivative spectra were evaluated and the concentrations of each compound were calculated, allowing the determination of the corresponding values of recovery and relative standard deviation (RSD).

\section{Photo-stability studies of PZQ and FBZ}

Individual solutions of PZQ and FBZ containing $4.0 \times 10^{-5} \mathrm{~mol} / \mathrm{L}$ of each drug in EtOH-HCl $0.1 \mathrm{~mol} / \mathrm{L}$ solution were used in photo-stability studies. The solutions were exposed to direct light, indirect light and darkness. The zeroorder spectra of each drug were evaluated every 30 min over 5 hours.

Simultaneous determination of PZQ and FBZ in pharmaceutical formulation (Tablet)

Ten Fentel ${ }^{\circledR}$ tablets were weighed and finely powdered. The average weight of tablets was determined with the help of the weight of 10 tablets. The nominal contain is $500 \mathrm{mg}$ of FBZ and $50 \mathrm{mg}$ of PZQ in the tablet. A quantity of $15 \mathrm{mg}$ of powder was weighed and diluted in $50 \mathrm{~mL}$ of EtOH-HCl $0.1 \mathrm{~mol} / \mathrm{L}$. The solution was in a sonic bath for $30 \mathrm{~min}$.

\section{RESULTS AND DISCUSSION}

\section{Solvent selection and spectral behavior}

The selection of solvent was based in find a solvent that satisfy the solubility of both drugs for the laboratory works. The spectral behavior should also be adapted to carry out the simultaneous determination for derivative spectrophotometry, developing a method, according to the analytical aims, of precision and accuracy. The solvents evaluated in this study for both drugs are shown in the Table 1 . Using EtOH-HCl $0.1 \mathrm{~mol} / \mathrm{L}$ the solubility and spectral behavior of both drugs shows the possibility of the simultaneous determination for these drugs (Fig. 2). It was also made a study of solvent in the pharmaceutical formulations, using EtOH-HCl 0.01 and $0.1 \mathrm{~mol} / \mathrm{L}$. The result shows that in $\mathrm{EtOH}-\mathrm{HCl} 0.01 \mathrm{~mol} / \mathrm{L}$ the tablets were slightly soluble and in EtOH-HCl 0.1 $\mathrm{mol} / \mathrm{L}$ were completely soluble. The solvent select for these simultaneous determinations was $\mathrm{EtOH}-\mathrm{HCl} 0.1 \mathrm{~mol} / \mathrm{L}$, because analytical signals are higher and defined for both drugs and the pharmaceutical formulation.

Table 1. Qualitative studies of the solubility of PZQ and FBZ $1.0 \times 10^{-3}$ $\mathrm{mol} / \mathrm{L}$.

\begin{tabular}{|c|c|c|}
\hline Solvent & PZQ & FBZ \\
\hline Acetonitrile & Not soluble & Not soluble \\
\hline Ethanol & Slightly soluble & Slightly soluble \\
\hline Methanol & Slightly soluble & Slightly soluble \\
\hline $\mathrm{HCl} 0.01 \mathrm{~mol} / \mathrm{L}$ in ethanol & Soluble & Soluble \\
\hline $\mathrm{HCl} 0.01 \mathrm{~mol} / \mathrm{L}$ in methanol & Soluble & Soluble \\
\hline $\mathrm{HCl} 0.1 \mathrm{~mol} / \mathrm{L}$ in ethanol & Soluble & Soluble \\
\hline $\mathrm{HCl} 0.1 \mathrm{~mol} / \mathrm{L}$ in methanol & Soluble & Soluble \\
\hline
\end{tabular}

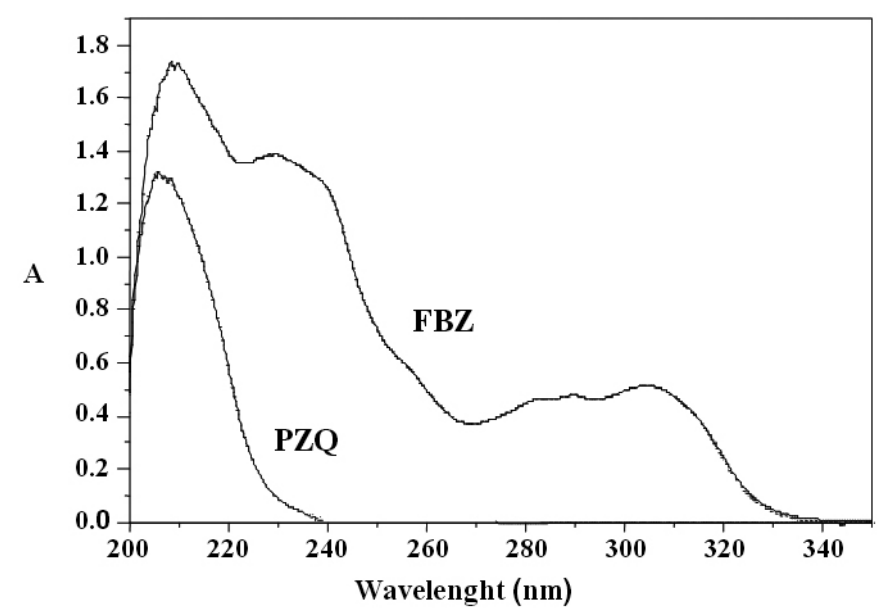

Figure 2. Zero-order spectra of PZQ and FBZ in EtOH-HCl $1.0 \mathrm{~mol} / \mathrm{L}$. PZQ 5.0 x $10^{-5} \mathrm{~mol} / \mathrm{L}$ and FBZ $5.0 \times 10^{-5} \mathrm{~mol} / \mathrm{L}$.

\section{Photo-stability studies}

In order to establish the photo stability of PZQ and FBZ in EtOH-HCl $0.10 \mathrm{~mol} / \mathrm{L}$, a $4.0 \times 10^{-5} \mathrm{~mol} / \mathrm{L}$ solution for each individual drug was used. All solutions were exposed to: direct light (sunlight), indirect light (laboratory light) and darkness for 5 hours by measuring the absorbance every 30 minutes. When exposed to indirect light and darkness none of the drugs change, since their zero-order spectra remained unchanged during the experiment. But when exposed to direct light only FBZ spectral behavior was altered (Fig. 3).

The zero order spectra of FBZ in EtOH-HCl $0.1 \mathrm{~mol} / \mathrm{L}$, has features such as signals two broad bands between 200 and $240 \mathrm{~nm}$ and between 260 and $330 \mathrm{~nm}$, as this drug is degraded photochemically, these signals disappeared and two bands appear, one centered at $230 \mathrm{~nm}$ and the other with two peaks centered at 285 and $295 \mathrm{~nm}$. These spectral changes evidenced a structural transformation as a result of photochemical decomposition in acid medium. Because of this, FBZ and FBZ degraded were analyzed by FT-IR (Fig. 4). 

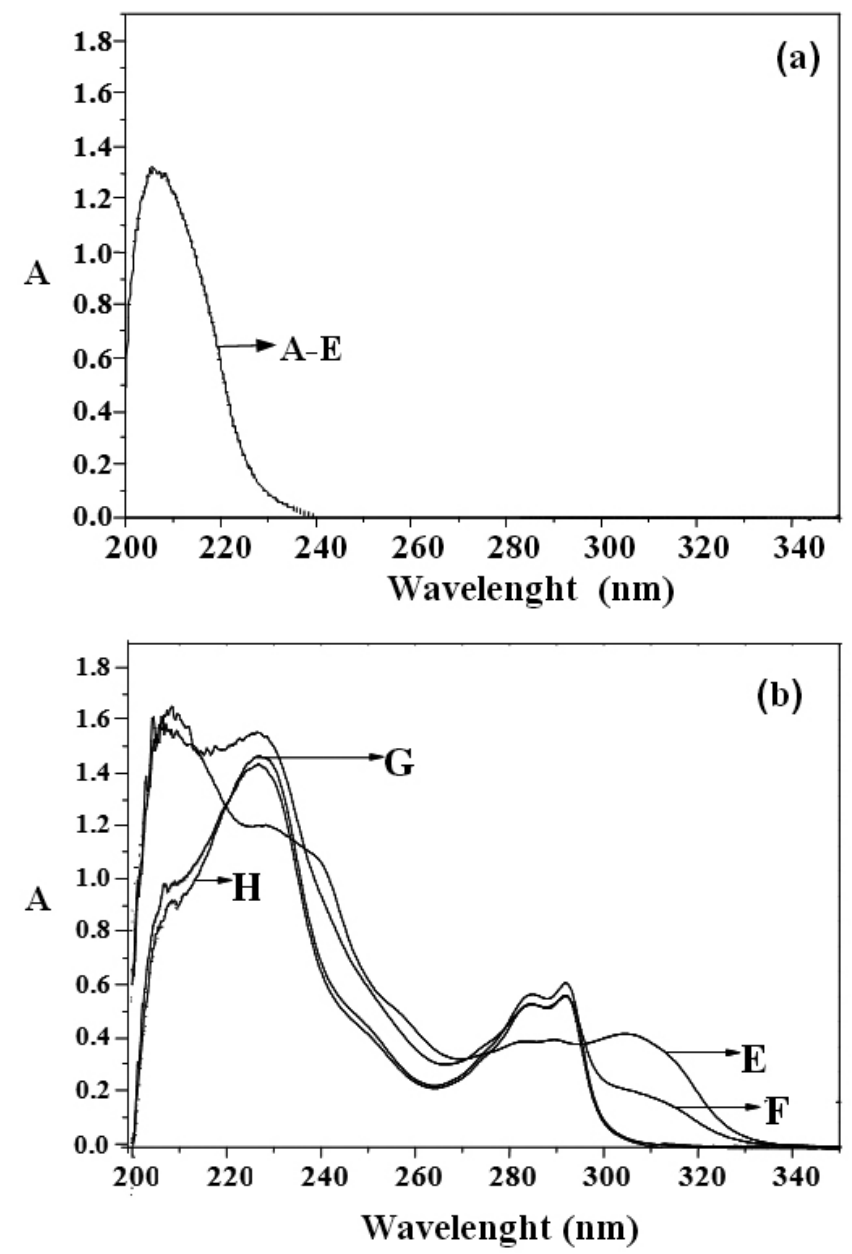

Figure 3. Effect of exposure time to direct light (sunligth) on zeroorder spectra of PZQ and FBZ in EtOH-HCl $0.1 \mathrm{~mol} / \mathrm{L}$, respectively. Drugs concentration $4.0 \times 10^{-5} \mathrm{~mol} / \mathrm{L}$. (a) PZQ (A) $0 \mathrm{~h}$, (B) $1 \mathrm{~h}$, (C) $3 \mathrm{~h}$ and (D) $5 \mathrm{~h}$. (b) FBZ (E) $0 \mathrm{~h},(\mathrm{~F}) 1 \mathrm{~h},(\mathrm{G}) 3 \mathrm{~h}$ and (H) $5 \mathrm{~h}$.

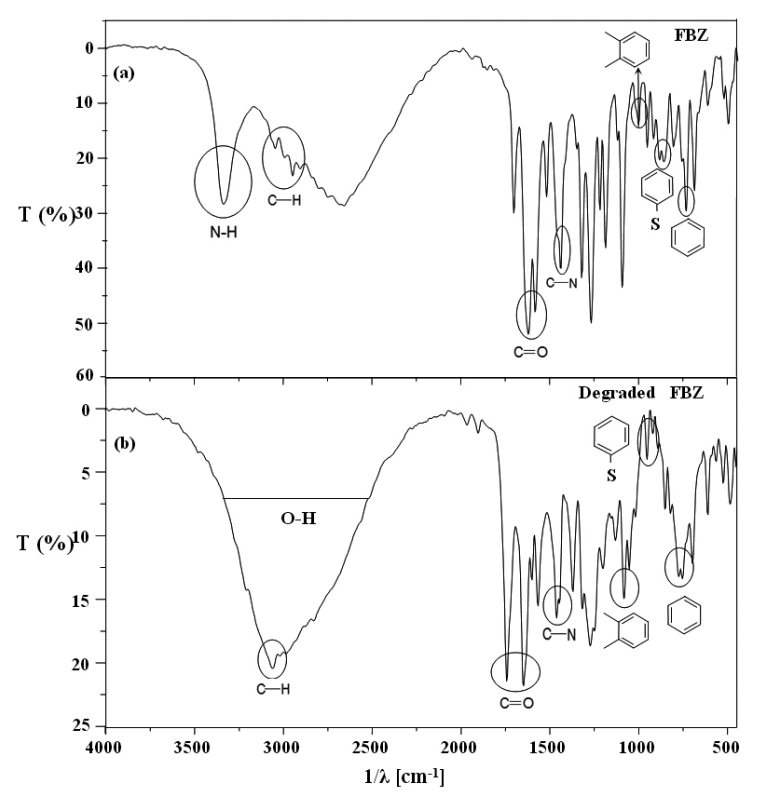

Figure 4. FT-IR spectra of: (a) FBZ recently prepared. (b) FBZ after $5 \mathrm{~h}$ of exposure to direct light (sunlight).
The IR spectrum shows signals of structural characteristics FBZ, highlighting the amide- $\mathrm{NH}$ group to $3336.3 \mathrm{~cm}^{-131}$, because this signal is not present in the FT-IR spectrum of FBZ degraded, indicating the existence of bond breaking of the amide group as a result of "stress" caused by sunlight for a time. Thus it is postulated that this break is of type photochemistry, since, when applied indirect light and darkness, no change in the spectral signals. Table 2 summarizes the assignment of FT-IR signals to FBZ and degraded FBZ. It is known that elucidate the mechanism of a photochemical reaction, has a high difficulty due to the high reactivity of the radicals formed, since these can react with any other species present in the reaction medium. Based on this, and knowledge of UV-Vis spectra start and end of the study, it was postulated a radical type reaction. Fig. 5 presents possible products. It should be noted that the method of analysis developed, is not invalidated, with the results previously obtained only if the solutions are not exposed to direct sunlight, since, when working under indirect light or darkness, the drug did not show any alteration in their spectral behavior. In fact, when the DU is plotted against time, there is constancy in the concentration of both drugs, confirming that the drug is degraded only if exposed to direct light (Fig. 6).

Table 2. Assignment of the functional groups in the spectra FT-IR for FBZ and degraded FBZ.

\begin{tabular}{|c|c|c|}
\hline Functional groups & $\begin{array}{c}\left.\mathbf{1} / \boldsymbol{\lambda} \mathbf{( c m}^{-1}\right) \\
\mathbf{F B Z}\end{array}$ & $\begin{array}{c}\mathbf{1} / \boldsymbol{\lambda}\left(\mathbf{c m}^{-1}\right) \\
\text { Degraded FBZ }\end{array}$ \\
\hline Tension C-H & $3050.9-2954.5$ & $3062.5-2985.3$ \\
\hline -N-H Amide & 3336.3 & - \\
\hline -C-N & 1442.5 & 1461.8 \\
\hline -C=O & 1708.6 & 1743.4 \\
\hline -C-O & 1222.7 & 1223 \\
\hline Fenil & 736.7 & 752.1 \\
\hline Fenil-(o) & 1099.2 & 1083.8 \\
\hline Bencenthiol & 690.4 & 694.3 \\
\hline -O-H Carboxílic & - & $3063.5-2831$ \\
\hline
\end{tabular}

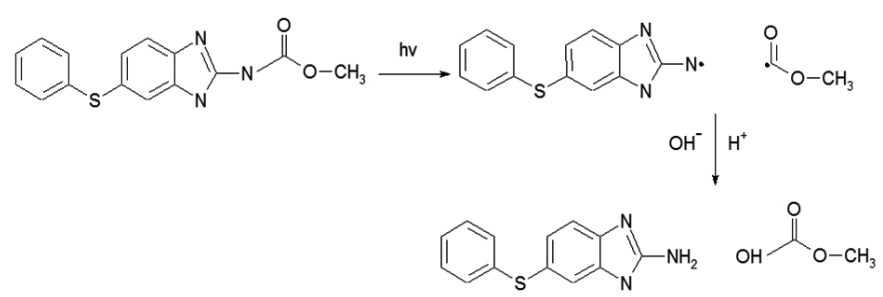

Figure 5. Schema of reaction postulated for the photochemical degradation of FBZ.

\section{Spectral features}

PZQ and FBZ were directly evaluated against the solvent selected, PZQ showed one maximum absorption peak centered at $205.8 \mathrm{~nm}$; under identical conditions FBZ presented three maximum absorption peaks centered at 304.4 , 229.6 and $208.8 \mathrm{~nm}$ (Fig. 2). Derivative spectrophotometry technique was used for the simultaneous determination of both drugs, since the spectral bands of the drugs under study are highly overlapping. 

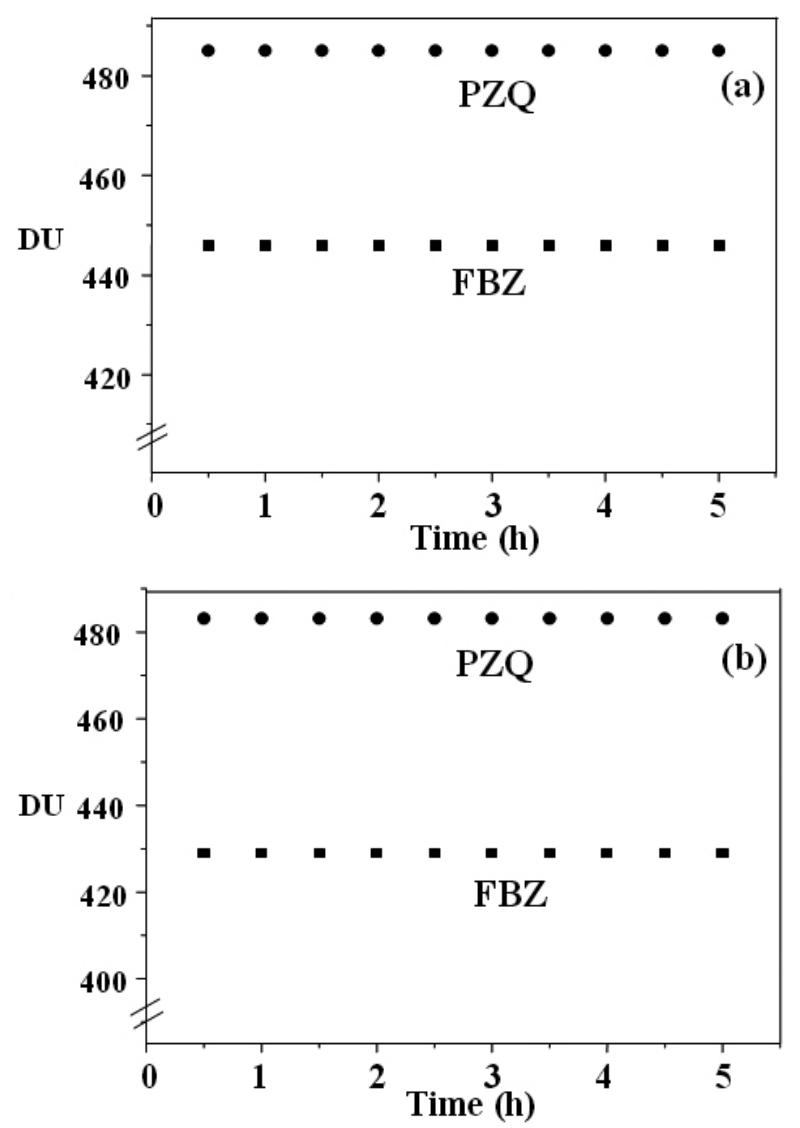

Figure 6. Photo-stability studies: (a) Indirect light (Laboratory light). (b) Darkness.

\section{Selection of spectral variables}

\section{Derivative order}

Different derivative orders of the spectra were obtained digitally from zeroorder spectra, this is based on a mathematic computational model proposed by Savitzky and Golay ${ }^{32}$, sacrificing the spectral resolution in order to increase strongly the signal/noise ratio, favoring the accuracy and the precision of the results and of the method, respectively. To select the optimum derivative order, the first to the fourth derivative spectra of the solutions containing separately the respective drugs were recorded. In Fig. 7 the first and second derivative are shown; third and fourth derivative order were discarded because the sensibilities and signal/noise ratio decreases. The first derivative spectra do not present zero crossing or zone characteristics for the simultaneous determination of both drugs, only the FBZ determination by graphic methods between 305.0 and $340.0 \mathrm{~nm}$ is possible. The first derivative is more sensitive that the second order, but this, present wavelength values for the simultaneous determination; for PZQ shows a zero-crossing at $226.4 \mathrm{~nm}$ and FBZ at $324.6 \mathrm{~nm}$ can be determined by graphic method. Because the resolution was satisfactory the second order derivative was selected.

\section{Selection of the smoothing and scale factor}

By using the derivative order selected (second), the smoothing factor could be optimized when the values defined by defect are varied, according to $\Delta \lambda$ value used to obtain the spectra. For a $\Delta \lambda$ of $150 \mathrm{~nm}$ the smoothing factor can be studied by taking the following values: 2,$000 ; 4,000 ; 8,000$ and 16,000 . The smoothing factor increment produces a decrease in the heights of derivative signal and a higher signal/noise ratio. The only smoothing factor value that produce a high signal/noise ratio was 8,000 , for this reason was selected. The scale factor must be studied to determine whether the system presents a distortion effect. To facilitate, the reading of the analytical signal, eliminate the distortion effects and not to affect the sensibility, a value of 100,000 was selected as scale factor.
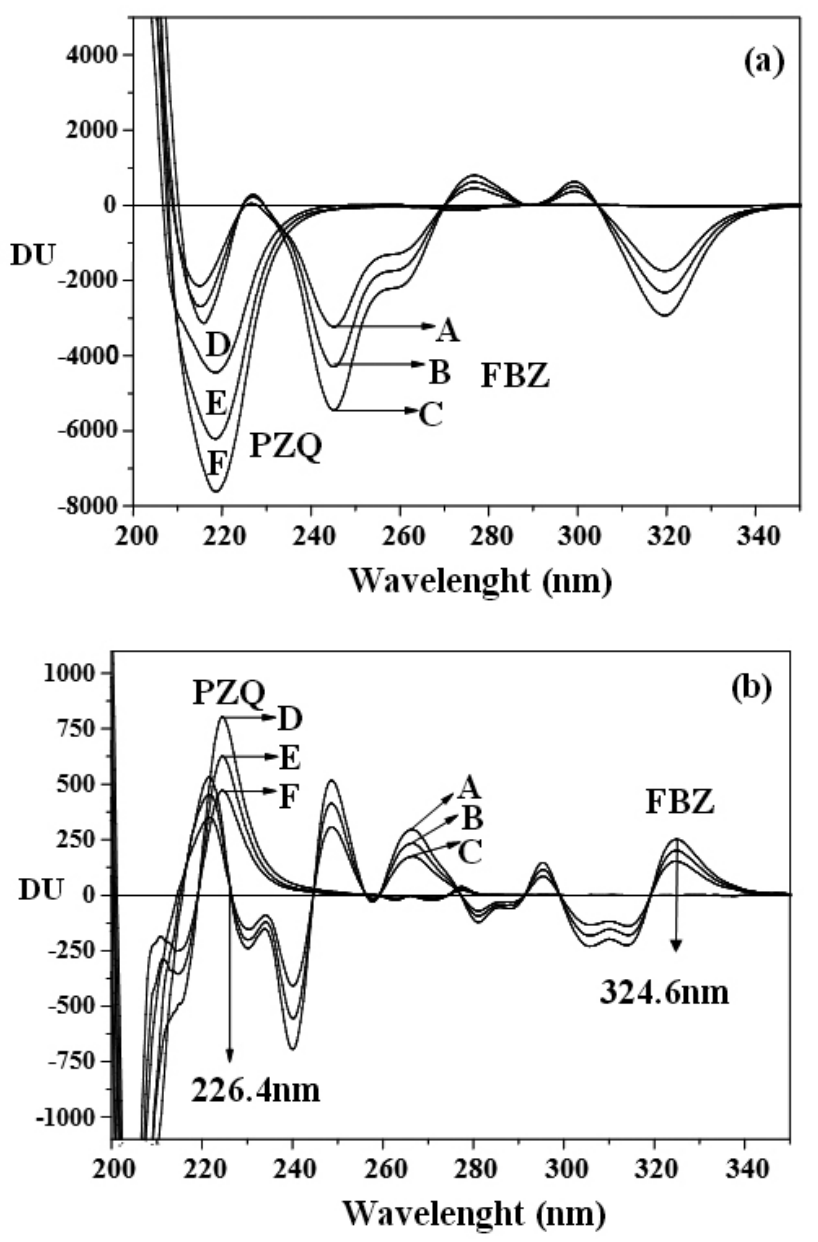

Figure 7. Derivative spectra of $\mathrm{PZQ}$ and $\mathrm{FBZ}$ in $\mathrm{HCl} 0.1 \mathrm{~mol} / \mathrm{L}$ in ethanol solution. (a) First order. (b) Second order. For both derivatives, FBZ: (A) 3.0 x $10^{-5}$ (B) $4.0 \times 10^{-5}$ (C) $5.0 \times 10^{-5} \mathrm{~mol} / \mathrm{L}$, PZQ: (D) $3.0 \times 10^{-5}$ (E) $4.0 \times 10^{-5}(\mathrm{~F})$ $5.0 \times 10^{-5} \mathrm{~mol} / \mathrm{L}$

\section{Analytical wavelength selection}

The analytical wavelength selection was carried out taking into account the second derivative signal of both analytes individually. FBZ determination was carried out by zero-crossing at 218.9, 266.2 and graphic methods between 320.0 and $330.0 \mathrm{~nm}$ (Fig. 7 b). $324.6 \mathrm{~nm}$ present analytical signals higher and well defined, furthermore presents the higher proportionality between DU and analyte concentration. Based on this, $324.6 \mathrm{~nm}$ was selected to the FBZ determination. FBZ second derivative signal show only one zerocrossing at $226.4 \mathrm{~nm}$ to the PZQ determination with high sensibility (Fig. 7 b). Based on this, $226.4 \mathrm{~nm}$ was selected to the PZQ determination. In order to select suitable analytical wavelengths is important to study the effect of the concentration of each drug on the other, in pharmaceutical formulation Fentel ${ }^{\circledR}$, with a molar ratio PZQ: FBZ of 1:10. Different mixtures contained both drugs, with concentrations of FBZ between $1.0 \times 10^{-5}$ to $5.0 \times 10^{-5} \mathrm{~mol} / \mathrm{L}$ and constant concentration PZQ $5.0 \times 10^{-6} \mathrm{~mol} / \mathrm{L}$, including the mass ratio contained in pharmaceutical formulations. After were evaluated used the optimum parameters, second-order derivative, smoothing factor 8,000 and scale factor 100,000 . The Fig. 8 includes spectra of a mixture of drugs with the pharmaceutical formulation mass ratio PZQ: FBZ and solution prepared from the tablet dissolved under the selected conditions containing: $5.0 \times 10^{-5}$ $\mathrm{mol} / \mathrm{L}$ of FBZ and $5.0 \times 10^{-6} \mathrm{~mol} / \mathrm{L}$ of PZQ. The independence of the analytical wavelength values selected of the drugs concentration, is experimentally demonstrated in Figure 8, both spectrum are similar. In these real samples also is possible the simultaneous determination of the drugs because the other compounds presents in the tablet do not affect the determination. 


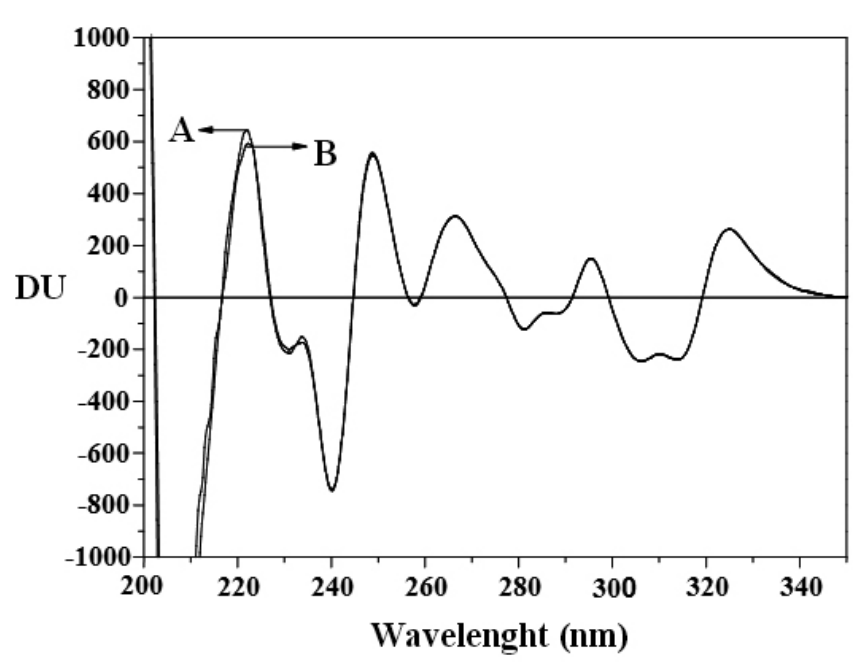

Figure 8. Spectra of the pharmaceutical formulation (A) and the synthetic mixture $5.0 \times 10^{-5} \mathrm{~mol} / \mathrm{L}$ of FBZ and $5.0 \times 10^{-6} \mathrm{~mol} / \mathrm{L}$ for PZQ (B).

\section{Analytical features}

Using the optimal parameters selected, a linear relation was observed between corresponding DU and the respective analytes concentrations. Calibration graphs were obtained by plotting the second derivative values for FBZ, DU $(\lambda=324.6 \mathrm{~nm})$ and PZQ, DU $(\lambda=226.4 \mathrm{~nm})$, using a smoothing factor of 8,000 , a scale factor of 100,000 and a $\Delta \lambda$ of $150 \mathrm{~nm}$, versus the respective drug concentrations. The criteria of the ICH Harmonized Tripartite Guideline were used for to obtain the analytical features. The following equations were used: $3 \sigma / \mathrm{S}$ and $10 \sigma / \mathrm{S}$, respectively, where $\mathrm{S}$ is the slope of the calibration curve and $\sigma$ the standard deviation corresponding to the response of 11 blanks to calculate the DL and QL.

The repeatability, expressed as relative standard deviation (RSD), was obtained by using 9 standard samples containing a mixture of the drugs in proportion 1:4, 1:6 and 1:9 (PZQ:FBZ). The determination range was defined between the QL and the loss of linearity. In this context, it is possible to obtain and an acceptable linearity degree with accuracy and precision in the results when the proposed method is applied. The results are show in Table 3.

Table 3. Analytical features.

\begin{tabular}{|c|c|c|}
\hline Analytical features & PZQ & FBZ \\
\hline Detection limit (mol/L) & $6.31 \times 10^{-8}$ & $1.96 \times 10^{-8}$ \\
\hline $\begin{array}{c}\text { Quantification limit } \\
(\mathrm{mol} / \mathrm{L})\end{array}$ & $2.10 \times 10^{-7}$ & $6.54 \times 10^{-8}$ \\
\hline $\begin{array}{c}\text { Determination range } \\
(\mathrm{mol} / \mathrm{L})\end{array}$ & $6.31 \times 10^{-8}-4.0 \times 10^{-4}$ & $1.96 \times 10^{-8}-1.0 \times 10^{-4}$ \\
\hline Repeatability (RSD, \%) & 2.19 & 0.57 \\
\hline Linear regression & $\begin{array}{c}\mathrm{DU}=1.764 \times 10^{7} \mathrm{C} \\
+1.979\end{array}$ & $\begin{array}{c}\mathrm{DU}=5.564 \times 10^{6} \mathrm{C} \\
-13.28\end{array}$ \\
\hline Correlation coefficient & 0.998 & 0.997 \\
\hline
\end{tabular}

The detection limits by chromatographic methods are lower than those obtained by this method; however, the limits obtained by UV-Vis are suitable for the simultaneous determination of these drugs in tablets ${ }^{33}$.

\section{Recovery in synthetic samples}

The accuracy of the method was tested for both analytes by analysis of synthetic samples. These solutions include the PZQ: FBZ ratio contained in the Fentel ${ }^{\circledR}$ tablet, it was necessary to establish the ratios at which one analyte can be accurately measured in the presence of the other; the recoveries of the samples containing standard solutions of mixtures of PZQ and FBZ in different concentration were carried out. The results are shown in Table 4. In the PZQ: FBZ molar ratios between 1:4 and 1:14 a good recoveries were found. The excipients normally found in tablets did not interfere in the developed methods. The developed methods have a wide application range and analytical utility.
Table 4. Recovery rates of PZQ and FBZ in different proportions.

\begin{tabular}{|c|c|c|}
\hline PZQ:FBZ & PZQ ( \% recovery) & FBZ (\% recovery) \\
\hline $1: 4$ & $94.6 \pm 6$ & $110.1 \pm 3$ \\
\hline $1: 6$ & $96.0 \pm 5$ & $116.9 \pm 1$ \\
\hline $1: 8$ & $98.4 \pm 3$ & $101.8 \pm 1$ \\
\hline $1: 10$ & $99.4 \pm 2$ & $98.1 \pm 1$ \\
\hline $1: 12$ & $115.1 \pm 14$ & $107.4 \pm 1$ \\
\hline $1: 14$ & $107.0 \pm 6$ & $104.7 \pm 4$ \\
\hline
\end{tabular}

Application of the proposed method

In the commercial pharmaceutical formulation Fentel $^{\circledR}$ the developed methods was applied. This formulation has a tablet average weight of $860 \mathrm{mg}$, containing nominally $500 \mathrm{mg}$ of FBZ and $50 \mathrm{mg}$ of PZQ. The results were satisfactory (Table 5).

Table 5.Simultaneous determination of PZQ and FBZ in veterinary pharmaceutical formulations.

\begin{tabular}{|c|c|c|}
\hline Drug & $\begin{array}{c}\text { Fentel }^{\circledR} \\
\text { (nominal content mg) }^{\text {mol }}\end{array}$ & $\begin{array}{c}\text { Amount found per tablet } \\
\text { mg }\end{array}$ \\
\hline FBZ & 500 & $490 \pm 6$ \\
\hline PZQ & 50 & $49 \pm 1$ \\
\hline
\end{tabular}

\section{CONCLUSIONS}

The spectral behavior for both drugs is different and according to the results obtained the simultaneous determination of the binary mixtures of FBZ and PZQ by second derivative spectrophotometry is effective. The proposed methods are accurate, precise, simple, less time-consuming, inexpensive and more sensitive. The recoveries of FBZ and PZQ from the synthetic samples, including the proportion contained in veterinary commercial pharmaceutical formulation, were near $100 \%$. The amounts found for both drugs are very similar to the nominal content in commercial tablets. Excipients contained in pharmaceutical matrix not affect significantly on the determination of the two analytes. Moreover the higher mass ratio present in tablets (PZQ: FBZ (1:10)) was overcome successfully.

\section{ACKNOWLEDGEMENTS}

The authors declare no conflict of interests and are grateful to the Dirección de Investigación de la Universidad de Concepción (DIUC) Project $\mathrm{N}^{\circ}$ 210.021.029-10, and the Fondo Nacional de Investigación en Ciencia y Tecnología (FONDECYT), Project No 1100103, for the financial support.

\section{REFERENCES}

1. V. Lopez-Avila, Crit. Rev. Anal. Chem. 29, 195, (1999).

2. D. Barcelo, M. Hennion, Anal. Chim. Acta 318, 1, (1995).

3. J. Arias, M. Lopez-Viota, B. Clares, M. Ruiz, J. Pharm. Sci-US. 34, 257, (2008).

4. W. Ridtitid, M. Wongnawa, W. Mahatthanatrakul, J. Punyo, M. Sunbhanich, J. Pharmaceut. Biomed. 28, 181, (2002).

5. M. Ghoneim, M. Mabrouk, A.Tawfik, J. Pharmaceut. Biomed. 30, 1311, (2002)

6. C. Ghazaei, J. Anim.Vet. Adv. 4, 852, (2005).

7. R. Lima, M. Ferreira, T. Ponte, M. Marques, E. Coelho, P. Bonato, L. Lanchote, J. Chromatogr. B: Anal. Technol. Biomed. Life Sci. 877, 3083, (2009).

8. A. Titus, M. Msagati, M. Muzi Nindi, J. Sep. Sci. 24, 606, (2001).

9. G. Morovjan, P. Csokan, L. Makranszki, E. Abdellah-Nagy, K. Toth, J. Chromatogr. A 797, 237, (1998).

10. L. Mottier, L. Alvarez, C. Lanusse, J. Chromatogr. B 798, 117, (2003).

11. W. Ridtitid, M. Wongnawa, W. Mahatthanatrakul, J. Punyo, M. Sunbhanich, J. Pharmaceut. Biomed. 28, 181, (2002).

12. A. Guzmán-Vázquez de Prada, O. Loaiza, B. Serra, D. Morales, P. Martínez-Ruiz, Anal. Bioanal. Chem. 388, 227, (2007).

13. M. Ghoneim, M. Mabrouk, A. Tawfik, J. Pharmaceut. Biomed. 30, 1311, (2002). 
14. H. Saleh and J. Schnekenburger, Analyst 117, 87, (1992).

15. C. Soto, D. Contreras, S. Orellana, J. Yañez, M.I. Toral, Anal. Sci. 26, 891, (2010).

16. A. de Prada, M. Mena, A. Reviejo, J. Pingarron, Anal. Lett. 37, 65, (2006).

17. J. Shen, J. Tong, H. Jiang, Q. Rao, N. Li, L. Guo, J. AOAC Int. 92, 1009, (2009).

18. H.Narayan, A. Mahendra, Res. J. Chem. Environ. 12, 45, (2008).

19. V. Hormazabal, M. Yndestad, J. Liq. Chromatogr. 18, 1231, (1995).

20. H. Saleh and J. Schnekenburger, Analyst 117, 1457, (1992).

21. S. Cholifah, A. Noviansari, W. Kartinasari, G. Indrayanto, J. Liq. Chromatogr. R.T. 30, 489, (2007).

22. T. Msagati, J. Ngila, S. Afr. J. Chem. 56, 5, (2003).

23. M. de Oliveira, N. Stradiotto, J. Pharmaceut. Biomed. 30, 279, (2002).

24. S. Ozkan, Curr. Pharm. Anal. 5, 127, (2009).

25. E. Kim, W. Hansel, D. Heber, Pharmazie 56, 146, (2001).
26. British Pharmacopoeia (Veterinary), Stationery Office, London, UK, 2001; pp. 50-51.

27. United States Pharmacopoeia USP33-NF27, Maryland, USA, (2008); pp. 3363.

28. United States Pharmacopoeia USP33-NF27, Maryland, USA, (2008); pp. 2350 .

29. C. Soto, D. Contreras, M. I. Toral, L. Basaez, J. Chil. Chem. Soc. $\mathbf{5 4}$, 2,113, (2009)

30. M. I. Toral, C. Soto, J. Rivas, M. Saldías, S. Orellana, J. Chil. Chem. Soc. 53, 2, 1543, (2008).

31. Socrates. G., Infrared characteristic group frequencies, $3^{\text {rd }}$ ed., Wiley $\&$ Blackwel, New York, (2001)

32. A. Savitzky and M. Golay, Anal. Chem. 36, 1627, (1964).

33. D. Ortelli, E. Cognard, P. Jan, P. Edder, J. Chromatogr. B 877, 2363 $2374,(2009)$. 